\title{
Talking about talk: Reviewing oracy in English primary education
}

Oracy is foundational to learning, at any age and in all subjects. Not only should it be developed in and of itself but it is a means of learning right across the curriculum. Within the $\mathrm{UK}$, despite rigorous and ground-breaking research into the fundamental importance of talk not only as a subject but as a means of learning in all subjects, the place of oracy in the curriculum and its associated policy initiatives have had a chequered history. The many fluctuations in educational policy over the last 30 years have meant that classroom talk has been both promoted and sidelined and its reform as part of the English curriculum, intensely political. Policy initiatives have given talk varying status relaying different messages as to its importance. This paper seeks to provide a review of the major policy initiatives and key research that have shaped the place of oracy within the classroom. It will argue that despite continued dispute between researchers and policy makers and the positioning of oracy as a contested field, there is a now a significant body of research which indicates the need for raising the status of oracy in order to impact both teaching and children's learning.

\section{Oracy, talk, speaking and listening: Definitions}

'Oracy' may be defined as the ability to understand and use spoken language. It is a term attributed to Andrew Wilkinson (1965) on making the case that it should be of equal importance to literacy. The term encapsulates the power of oracy which functions not merely as a 'subject' but as 'a condition of learning... not [as] a 'frill' but a state of being in which the whole school must operate' (cited in Corden, 1988.1) However, within various iterations of the UK English National Curriculum, the term 'Speaking and Listening' has been used but criticised for failing to acknowledge their inter-relatedness, so promoting a false dichotomy between the two functions. It has been described in the Cambridge Primary Review of the Curriculum (2010) as used to label a curriculum which is 'conceptually weak and insufficiently demanding in practice' (p 269). In the most recent English National Curriculum (2014) the term has now been replaced by 'Spoken Language' but this again has been denounced for not having the 'connotation of acquired skill that, by analogy with literacy, 'oracy' possesses' (Alexander, 2012.2).

\section{A rationale for talk}


Talk is integral to learning. Vygotsky (1962) recognised the interrelationship between language and thought, interaction and development. He acknowledged that using language to communicate is central to the development of new ways of thinking and that interaction with a more advanced peer/adult within the 'zone of proximal development' (that is the gap between what they can do alone and what they can achieve with assistance) places social interaction at the heart of the learning process which is where thinking originates. As Lefstein (2014) observes, 'the ways of talking into which we are socialised shape both the cognitive tools at our disposal and the habits of mind whereby we put those tools to use' ( $\mathrm{p} 18)$. For Vygotsky, thinking and talk are first social and subsequently become individual. Talk is grounded in social contexts representing different meanings and as such children engage not merely in activities but in making meaning (Barnes, 2010).

Constructivist views on the nature of learning require the learner to 'work on understanding' which is primarily achieved through talk. Undertaken within the school context, social constructivism places collaborative approaches at the heart of learning. Learning occurs through talk between children and between teachers and children as rehearsing ideas through speaking become new ways of thinking. Bakhtin (1981) describes the dialogic nature of language which permeates both spoken and written discourse and must therefore be at the heart of learning new frames of reference. This socio-cultural view requires individuals to be active participants in their own learning and exercise greater control over it by means of talk.

\section{Early research in England}

As far back as 1928, the Newbolt Report acknowledged the importance of spoken language as foundational both to the teaching of English and particularly to pupil's progress in writing. Further it warned against the dangers of imposing standard English at the expense of pupils' own dialects (Gibbons, 2015). However, it was not until significantly later that the impact of these ideas was outworked in practice. Foundational to research and practice on talk was the work of early researchers in the 1960's and 1970's. The work of the London Association of Teachers of English (LATE) and subsequently the National Association of Teachers of English (NATE) founded in 1963, although having a secondary focus ( ages 11-18), were comprised of teachers and academics who explored the links between language and experience, highlighting the importance of pupils' use of talk to order their experience and 
thereby learn. Influential within this group were Andrew Wilkinson, James Britton and Harold Rosen. Wilkinson's work focussed on how children learned through talk within classroom contexts and had a particular focus on the benefits of small group collaboration (Wilkinson et al., 1965). He observed the ways in which children's spoken language developed in a social context by imitating others and being stimulated by their responses (Howe, 1992). As noted above, he coined the term 'oracy', using it to define a 'condition of learning' which should go across all subjects and pervade the whole school. Rosen's specific interest lay in children's use of dialect and the importance of allowing them to use the language of the home in the school context as a means of learning whereas Britton's particular focus was on language development and thought and in championing the importance of spoken language (1994). He utilised Vygotsky's theories to underpin beliefs and findings about the links between language and thought and the social construction of knowledge so providing a strong theoretical framework for research (Gibbons, 2015).

Also highly significant at this time was the work of Douglas Barnes in inner city classrooms in Leeds. Barnes' seminal work, 'From Communication to Curriculum' (1976) was based on research into classroom talk, revealing how children's talk and thereby learning, was restricted in contexts where their responses were limited within teacher dominated patterns of classroom interaction. A fundamental belief of these key scholars was that 'children learned through talk; it was not simply a language mode used to communicate understanding' (Gibbon, 2015, p159). As a result the importance of talk was acknowledged not merely within the confines of English, but within all subjects across the entire curriculum. The essence of their thinking is powerfully illustrated in the following quotation:

We sharpen our understanding by telling or attempting to explain to others. As we hear ourselves say what we think we can monitor this objectification of our thoughts... Without plentiful experience of talking things through, we would be denied access to that inner speech through which we organise our thinking. (Barnes, Britton and Rosen, 1969, p cited in Coultas, 2015)

The significance of this work could not be underestimated given the particular historical, social and educational milieu. 


\section{Bullock, Kingman, Cox: significant reports}

The Bullock report, 'A Language for Life' (1975) recognised the empowerment that valuing the language of the child could bring and encapsulated much of the early research above. It stated that a child should not be expected to cast off the culture or language of the home and highlighted oral language as fundamental to learning across the entire curriculum. It acknowledged that children's development in language was dependant on the integration of reading writing and talk. Yet although lauded, resulting action in terms of practice was debateable. Nevertheless the Bullock report functioned to raise the status of talk as fundamental to children's learning across the curriculum.

This was echoed by the Kingman and Cox reports of 1988 and 1989 respectively which specifically cited teachers' and pupils' lack of knowledge about language (KAL) as impeding progress in teaching and learning. While the Cox Report formed the basis for the first English National Curriculum, the Kingman Report was essentially a response to a perceived decline in standards in the teaching of language. Kingman received a certain level of criticism in relation to its lack of theoretical rigour. This was attributed to a range of factors, not least the membership of the committee which comprised both academics and lay people, the latter perhaps deriving their understanding from "more populist views of the English language, and more particularly 'standard English"” (Bex and Watt, 2000, p.90). Confusion about understandings of the role of spoken language including standard English (connected to interpretations of 'standard' as being 'uniform' or 'excellent' (Crowley, 1997) underpinned the Kingman Report which was a response to the kind of complaints about declines in standards that frequently appeared in the media. It reflected how, in the public consciousness, attitudes to standard English and "correct" use of grammar can be linked to "good" and "bad" language: good and bad people. However, Carter, who was to become instrumental in bringing about change, while not explicitly criticising the Kingman Report (1998), highlighted the need to develop the model of language that it assumed (1990).

\section{Influential talk projects}

As a result of these 2 major reports, the Language in the National Curriculum (LINC) project (1990), headed by Ron Carter, was set up. This was a major government funded initiative, the 
remit of which was to provide in service training and produce materials which would support teachers' KAL. It was designed primarily to strengthen their knowledge and understanding of language in order to implement the effective introduction of the English National Curriculum. Essentially, it did not set out to teach teachers how to each, rather it sought to enhance teachers' KAL in its widest sense to enable them to implement the recommendations of the English National Curriculum. From the beginning it was evident that the approach adopted by the Project Director, Professor Ron Carter and his team of "Expert Trainers" would take a far broader perspective on the concept of language teaching than the grammar textbook that was envisaged by the government. Carter, (1999) states explicitly that the LINC materials and its accompanying reader aim to develop the model of language embedded in both the Kingman and the Cox Reports, particularly in relation to the social and cultural variations of language. The LINC Project adopted a sociolinguistic model of language (Halliday 1987) advocating a three dimensional approach to language education: dialectal (regional and social); diatypic (functional) and diachronic (historical).

"...for any theory of language in education, it should be seen as the norm, rather than the exception, that the community of learners use a variety of codes (languages and dialects), that they use a variety of language functions (or registers), and that none of these ever stands still." (Halliday, M. (1987) in Carter, R. (ed.) (1990 p.1)

In addition, it assumed Britton's theories on language development highlighting the "essential nature of cultural values and beliefs that determine the purposes, audiences, settings and topics of language". (ibid. p.10). These were the principles that essentially underpinned the LINC Project and its related materials giving powerful messages about spoken language and its status and development in schools.

Such perspectives need to be considered against a backdrop of heated debate in both the political and educational fields which surrounded the introduction of the first English National Curriculum. Until this point, the teaching of language and, in particular, grammar had been characterised by a prescriptive model in which correctness in the use of language was emphasised. Language teaching often focussed on decontextualised exercises in which children filled in missing words or identified parts of speech. Spoken language rarely provided the explicit focus for teaching and, indeed, children's talk was not always actively encouraged in the classroom. 
In this context then, the LINC Reader and its materials could be perceived as a radical development from the model of language and standard English assumed by the Kingman Report (1988). They offered the opportunity for an informed debate on many issues surrounding the teaching of English. LINC presented a theory-based approach to the teaching of spoken language and standard English, aiming to celebrate the richness and variety of the English language through developing children's speaking and listening, reading and writing repertoires. It maintained that in order to overcome prejudices about spoken language embedded in society, including the use of non-standard dialects, teachers needed to be informed about current linguistic theory.

However, there arose a fundamental disagreement between the project leaders and the government who took issue with the view of language promoted and in 1993 the government withdrew its funding, objecting to the project's sociolinguistic approach, its 'alleged appeal to cultural and linguistic relativism and its failure to uphold the cause of standard English' (Alexander, 2012:7). Although controversial with government and politicians, the project proved popular with teachers and academics, and continues to inform the curriculum within higher education departments across the UK. Such criticisms however have been at the heart of the debate on talk, impacting its status and prominence within the various iterations of the National Curriculum and associated policy documents.

The late eighties and early nineties proved to be a rich era in teaching where the profile of oracy was high and debate fierce. Networks of teachers began working around the UK on various language based projects, many of which saw talk as their central focus, for example the Inner London Education Authority (ILEA) oracy project. In 1987 another key initiative the National Oracy Project (NOP), sought to specifically address teachers' knowledge about talk and to develop both their understanding and practice. As part of the project, networks of teachers were set up working collaboratively on promoting talk within their classrooms and encouraging children's active learning. Action research was integral to this approach, teachers investigating children's spoken language, observing and recording their talk and exploring children's own reflections on themselves as talkers (Johnson, 1994). It promoted group work in the classroom and was advocated at the time as a way of widening the teacher's repertoire for classroom organisation... taking pupils through several stages of learning, exploration, transformation, presentation and review' (Coultas 2015.77). This project raised the profile of talk considerably and heightened teachers' understanding and 
awareness of the importance of talk in its own right and as a means of learning. However, although the legacy of both the NOP and LINC projects can be traced in academia and schools, both disappeared from the public scene in the following years as the first English National Curriculum was established from 1989.

\section{The National Curriculum and National Literacy Strategy}

The introduction of the National Curriculum in 1989 was significant as far as English was concerned as it saw 'Speaking and Listening' for the first time being given equal status with 'Reading' and 'Writing' as the main components of the English Curriculum. It demonstrated a conviction that speaking and listening was central to children's overall language development. The impact of this was to drive consideration of what it meant for teachers to focus on talk in the classroom and also created an imperative for them to assess it. What had previously been for teachers to decide in terms of curriculum content, was now enshrined in law as the teaching and assessment of Speaking and Listening as an Attainment Target became compulsory. Although it defined a body of knowledge in English that should be taught, it was criticised as ambiguous and liberal by those driving the standards agenda who advocated a significantly more prescriptive curriculum (Cox 1991; Coultas, 2015).

In 1998 the National Literacy Strategy was introduced placing its greatest emphasis on 'Reading' and 'Writing' to the neglect of 'Speaking and Listening'. Its agenda was to support teachers in raising standards of literacy. The NLS framework introduced the structured 'Literacy Hour' into primary classrooms with specified components of whole class introduction, followed by independent group work (which could take the form of guided reading and writing sessions) and subsequent whole class plenary. A 'pacy, interactive oral exchange' was recommended as part of teaching sessions as was the use of 'interactive, whole class teaching.' This emphasis was re-iterated within the revised National Curriculum (DfEE/QCA, 1999) which highlighted the importance of group discussion and interaction.

In 2003 the Literacy Strategy and its parallel Numeracy Strategy were merged to become the Primary National Strategy (PNS) at which point talk had been omitted from the new documentation, literacy being narrowly defined as reading and writing. Although some have noted that the importance of speaking and listening was implicit within the documentation (Grugeon, 2005), it was clearly not explicit. Its manifesto Excellence and Enjoyment: $a$ 
strategy for primary schools (QCA/DfES, 2003) failed to mention talk and failed to engage with research evidence (Alexander, 2004). In response to objections concerning this omission, speaking and listening was re-instated to some degree in subsequent supporting materials for example Speaking, Listening and Learning: working with children in Key Stages 1 and 2 (QCA/DfES, 2003) which emphasised the cross-curricular nature of speaking and listening objectives within the PNS. Progression was outlined in relation to the four strands of Speaking, Listening, Group Discussion and Interaction, and Drama. Embedded within these materials was a call to teach through dialogue, enabling 'teachers and pupils to share and build on ideas through sustained talk' ( $p$ 35)

However, these materials did not receive the same attention as those promoting reading and writing, schools' responses to implementing the guidance being best described as tentative. Subsequent to the release of PNS documentation, the Rose Report was published (2006). Although its primary focus was the teaching of early reading it did emphasise the need to develop children's speaking and listening from the early years, acknowledging that along with reading and writing, speaking and listening are central to children's social and emotional development. The gradual re-emergence of the importance of talk was confirmed in the National Strategy's re-worked guidance (PNS Framework for Literacy, 2006) which mirrored more closely the National Curriculum (1999) and identified 12 interrelated strands for teaching literacy with speaking, listening, group discussion and interaction at the fore. In the same year however Ofsted's survey of speaking and listening in schools (2006) acknowledged that this aspect had not enjoyed the prevalence it deserved in terms of teachers time \& attention. It recognised that in order to improve provision for speaking and listening, teachers' understanding of the nature of talk needed to be enhanced; the use of drama techniques should be extended and speaking and listening (including standard English) should be taught directly.

\section{The National Curriculum and National Strategy: impact on practice}

A significant amount of post NLS research suggests that the strategy and its related documentation has had little effect either on raising children's competence in spoken language or on enabling teachers to provide a rich environment where classroom talk is integral to the learning and teaching process. Mroz et al (2000) (cited in Coles, 2005) note 
that the Literacy Hour has spawned more 'teacher-led recitation' (p380) where questioning and the exploration of ideas rarely occur. English et als' research (2002) revealed that at Key Stage 1 (5-7 age group) children's spoken contributions were rarely longer than 3 words $(10 \%)$ or even 5 words $(5 \%)$ and furthermore, that responses entailed 3 or fewer words for 90\% of classroom time. The work of Elmer and Riley (2001) revealed that the length of interactions had lessened and teacher questions had become lacking in both rigour and challenge, while others observed that the teacher dominated nature of interaction pervaded work in classrooms (Burns \& Myhill, 2004). A further study by Smith et al (2004) revealed that during Literacy Hours, although highly structured question and answer sequences were used, most questions were closed and of a low cognitive level, few pupils initiated questioning and their exchanges were short. In essence, it was found that 'top down' curriculum initiatives like the...NLS, while bringing about a scenario of change in curriculum design, often leave deeper levels of pedagogy untouched' (Smith et al, 2004. 409, cited in Grugeon et al, 2005). Such findings however are not new or simply related to NC/NLS initiatives. A succession of studies across a significant time span has demonstrated the nature of classroom talk as frequently teacher dominated and characterised by rigid forms of teacher dialogue (Barnes, 1972; Myhill, 2006;).

\section{Spoken English in the classroom: new perspectives}

The National Literacy Strategy (1998) then clearly did not have the desired impact on raising standards. In the context of criticism of the effect on teaching in primary classrooms and the prevalence of 'low level interactions', a re-emergence of the importance of speaking and listening prompted two Qualifications and Curriculum Authority (QCA) conferences followed by a series of discussion papers, "New Perspectives on Spoken English in the Classroom" (QCA, 2003) which reflected both sociolinguistic and sociocultural perspectives. Key themes emerging from these diverse papers were the role of a grammar for spoken language for underpinning teachers' subject knowledge and pedagogy in teaching speaking and listening (Carter and Cameron 2003), the role of talk in children's learning and how this is facilitated through teacher-pupil interactions (Alexander 2003) and a critique of the narrow view of speaking and listening presented in government policy documents (Cameron, 2003). Contributors to 'New Perspectives' described what characterises dialogic talk, contrasting it with the kind of 'arid discursive transactions most commonly observed in British classrooms' (Moyles 2010, p119) 
The need to respond to teachers' lack of confidence in how to teach speaking and listening was highlighted together with what teachers need to know about spoken language in order to teach it effectively in the classroom. Because spoken language had largely been under theorised, teachers' understanding of how to teach speaking and listening should be underpinned by the knowledge that the grammars of spoken iand written English differ. If models of written grammar are applied to spoken English, speech can often be perceived as an "inferior" form of language which deviates from written grammatical conventions. Consequently, fundamental to effective classroom practice is the need for teachers to develop an understanding of the grammar of spoken English (Carter, 2003).

Coffin, (2003) contextualises the need for teachers to develop an understanding of the grammar of spoken language from the perspective of functional grammar (the model embedded in both the LINC materials and the LINC reader) as it encapsulates both social and linguistic models of language. She identifies three reasons why teachers should gain a more explicit understanding of functional grammar: for educational diagnosis; curriculum design and for the development of teacher talk. The first of these purposes, the diagnostic function is particularly pertinent as Coffin argues that "professional understanding of grammatical structure can help teachers to recognise the linguistic basis of learners' difficulties and the ways in which grammatical repertoires may need to be extended" (2003 p.15). This knowledge could then inform teachers' future planning by providing more challenging and varied contexts for children to develop their linguistic range. Her argument continues by identifying the need for a metalanguage, a shared language about the grammar of talk, which would facilitate a "shared language for professional exchange" (p. 17).

\section{Key research to date}

The work of the early researchers from the 1960s has been foundational to research on oral pedagogy to the present day. Drawing upon constructivist and social constructivist theories, Barnes developed his ideas about the nature of classroom talk, distinguishing between the two functions of exploratory talk (by which pupils try out ideas and organise their own thoughts ) and presentational where talk is adjusted to the needs of an audience. He has continued to explore ways in which both types of talk are fundamental to learning (Barnes, 
$1976,1988,2010)$. This socio-cultural view requires individuals to be active participants in their own learning and exercise greater control over it by means of talk.

Building on this, significant work into the relationship between social, cognitive and communicative aspects of talk and how this connects with learning has been carried out (Evans and Jones, 2008). In their focus on learning as a social process, Edwards and Mercer (1987) use the term 'common knowledge' to describe the ways in which learning takes place in the interaction between teacher and pupil. How teachers behave in lessons and how they receive and use their pupils 'spoken and written contributions, is crucial in shaping how pupils will set about learning and therefore what they will learn' (Barnes in Mercer 2010, p9). As such, teachers should make explicit to children the ways in which they learn and enable reflection on learning in order to promote critical thinking. The role and response of the teacher then has a powerful impact on the learning process as it 'validates' or otherwise, the children's thinking and may, or may not facilitate learning.

Further work on group interaction has continued to inform teachers about the ways children learn through talk. Within the influential 'Talk and Reasoning at the Computer' (TRAC) project, for example, Mercer (2000) specified four types of talk, playful, disputational, cumulative and exploratory suggesting that if children are to effectively engage in exploratory talk, then they need explicit teaching of 'ground rules' which involves children understanding and engaging with the ways in which talk enables effective learning. Further research has been undertaken into how exploratory talk within group discussions can impact the ways in which teachers and children interact, highlighting the importance of collaborative thinking and problem solving. (Mercer and Littleton, 2007) The term interthinking has been employed to describe a specific process: 'by using spoken language people are able to think creatively and productively together... people do not use talk only to interact, they interthink (Mercer \& Littleton, 2013, p1). From this, a practical approach to facilitating learning through talk in schools, Thinking Together, has been developed (Mercer and Dawes, 2010).

These approaches present a view of talk in the classroom which contrasts greatly with the research describing discourse patterns in post NLS classrooms above, as do international research findings on classroom talk (Alexander, 2003). In England the Initiation, Response, Feedback exchange (IRF) (Sinclair and Coulthard, 1975) predominates in primary classrooms as the major pattern of teacher-pupil interaction. Here teachers initiate, pupils respond then 
teachers close down the exchange with brief feedback. In addition, the status of oracy in England is described as "at best a poor relation" (Alexander, 2003, p. 28) to reading and writing. The way in which talk is perceived in the classroom reflects "underlying assumptions and beliefs about the nature of teaching and learning... and the ways in which the individual should stand in relation to others and society as a whole" (ibid. p36). In maintaining the key values that underpin teaching are based on how people should relate to each other, Alexander argues that English primary education leans towards "individualistic and communal practices" (ibid. p.29); These values manifest themselves in primary pedagogy in relation to the individual, the group and the class, discourse patterns in English primary classrooms revealing some interesting contradictions. Although children may be organised to work in groups, they tend to operate as individuals within those groups and in whole-class teaching, the child tends to respond as an individual to the teacher, not to the whole class

The discourse patterns noted in English classrooms were characterised by "ambiguity and dissonance" (ibid. p32) in that underpinning the conversational nature of the talk, the power lay firmly in the grasp of the teacher and questions asked did not promote effective dialogue. "'If an answer does not give rise to a new question from itself, then it falls out of the dialogue." (Bakhtin 1981 in Alexander 2003 p.32). In critiquing what kind of "communicative competence" (ibid. p33) is generated in these interchanges an alternative model for classroom interactions, dialogic teaching is presented. Essentially, this involves a shift in the power relations in primary classrooms and a culture for talk where children feel free to hypothesise and give incorrect answers. It advocates an approach where teachers and children work together on problems, listening to each other and sharing ideas into "coherent lines of thinking and enquiry" (ibid. p.36). At the heart of this is an approach which moves teachers away from unthinking use of IRF. 'Helping teachers to transform IRF sequence into purposeful and productive dialogue is fundamental' what is needed is in-service training for teachers which 'emphasises joint teacher-student activity and higher order thinking through a dialogic pedagogy' (Hardman, 2011, p 45).

Underpinned by Vygostsky (1962) and Bakhtin (1981) such an approach 'provides the best chance for children to develop the diverse learning talk repertoire on which different kinds of thinking and understanding are predicated' (Alexander, 2010, p105) and is characterised by the following: it is collective as children and teachers work together; reciprocal, children and teachers actively listening to each other; supportive in that learning takes place in risk-free 
environments; cumulative teachers and children building on each other's' thinking and purposeful, teachers having clearly defined goals for talk. Several dialogic teaching projects have been undertaken within the UK which have continued to explore classroom talk (Alexander, 2003; 2005a; 2005b). Findings reveal that whereas progress has been made with the first three criteria, teachers find the last two most challenging: 'Recitation remains the default teaching mode...feedback [can] become phatic or uninformative...but dialogue requires an interactive loop or spiral rather than linearity' (Alexander, 2010). Clearly then there is more work to be done in supporting teachers towards confident knowledge and understanding of meaningful patterns of classroom discourse.

\section{Conclusion}

For decades the place of talk has emerged and re-emerged within the wider debate on standards. As far back as 1988, Sheila Lawlor, deputy director of the influential Centre for Policy Studies, a right wing Conservative think tank, maintained that there was "no reason to suggest that children learn from talking' (Lawlor, cited by Jones, 1989, p66). Decades later, a recent statement by the former Secretary of State for Education, Michael Gove, criticised educational theorists who 'have consistently argued for ways of organising classrooms and classroom activity which reduce the teacher's central role in education. All too often, we've seen an over-emphasis on group work - in practice, children chatting to each other - in the belief that is a more productive way to acquire knowledge than attending to an expert.(Gove,2013 https://www.gov.uk/government/speeches/michael-gove-speaks-aboutthe-importance-of-teaching ). There exists a reluctance to engage with research. Currently, the 'back to basics' agenda, pervades the rhetoric of the current minister for Education, Nicky Morgan. Reading and writing are viewed as pre-eminent to the detriment of talk in UK classrooms.

Analysis of key policy texts and initiatives reveals the divergent nature of national policy over time. Rather than the piecemeal and disparate approach to national policy on talk which has characterised the last thirty years, a 'radical act of joined-up policy' has been called for in order to 'secure leverage on the quality of classroom talk' (Alexander, 2012:1).

It is time for policy makers to engage with the substantial body of growing research evidence. Not only has it been established that talk is essential to children's thinking and learning 
(Vygotsky, 1962; Bahktin, 2013) but there is also strong evidence to show that high quality classroom talk gives pupils greater control over their own learning and contributes to their successful functioning in society (Barnes, 1976; Hardman, 2004; Myhill, 2006; Lefstein 2014;). Additionally, it impacts standards of attainment not only in English, but across the entire curriculum (Resnick, 2011). Given that classroom talk is 'the most important educational tool for guiding the development of thinking and for jointly constructing knowledge' (Mercer and Hodgkinson, 2009:11) right across the curriculum, it is clear that policy should support the development of teachers' knowledge, understanding and pedagogy.

Teachers' knowledge and understanding has not been supported by disjointed policy. Further, the confusion inherent within documentation, for example the NLS, appropriated the language of constructivism but its training materials exemplified more didactic forms of teaching. 'An absence of pedagogic rationale..[made] it nearly impossible for teachers to disentangle the inherent ideological contradictions at the heart of [the] materials' (Coles, 2005 p114). Within this and subsequent National Curriculum documentation, the place of spoken language being at the heart of teaching and learning and the value placed on it within the classroom is certainly debateable and at best tokenistic. Superficial, under theorised training materials operating at the level of 'tips' are not required, rather a clear understanding of grammar, linguistics and how this drives effective practice is called for. We are at a stage where the message of Cox continues to be pertinent and the call of Kingman for increased KAL remains relevant. Further, the explicit knowledge about language presented within the LINC materials is still needed to inform teachers' understanding of what children achieve in both their spoken and written language:

“...if teachers have no formal training in linguistic awareness then they will lack categories and frameworks for thinking about and analysing crucial elements in learning and will therefore draw such categories from a common core of half-belief in which prejudice and fact combine indistinguishably."

(Carter, R. ibid. p. 17)

The politically independent Cambridge Primary Review (2010), a comprehensive enquiry into English Primary education made the following statement: '...in England literacy is too narrowly conceived and...spoken language has yet to secure the place in primary education 
that its centrality to learning, culture and life requires' (p269). The review goes on to recommend that the National Oracy Project should once again be a point of focus and that this, together with other more recent research should inform the place of oracy within any subsequent national curricula.

However, the latest National Curriculum (2014) has further downgraded talk, or 'Spoken Language', being reduced to twelve statements in contrast to the significantly greater emphasis being placed on 'Reading' and 'Writing'. In this curriculum, traditional models including presentational talk, recitation of poetry and standard English are emphasised. The current climate is one where the debate on standards is prevalent within a culture of increased testing and accountability of both schools and teachers. This is not a context which encourages teachers to deviate from curriculum emphases which are tested and prescribed. It is a context however in which innovative research and practice continues and in which talk as a means of learning and a subject in its own right, deserves to be acknowledged and promoted by government and policy makers. The complexity of the nature of talk as fundamental to learning and teaching needs to be upheld:

"When we talk...the information [we process] is not just linguistic, but also cognitive, semiotic and sociocultural. The processes involved are dynamic, constantly changing and fluctuating as new meanings emerge, and they often place demands on speakers and listeners that can reveal them at their most exposed in their identities as people" (Carter, 2003, p.77)

Talk is inextricably linked not only to cognition and learning but to identities, a sense of self and what it means to be human. In its capacity to empower both learners and teachers, it deserves to be given its rightful place within the curriculum.

Bibliography

Alexander, R.J. (2001a) Culture and Pedagogy: International Comparisons in Primary Education Oxford: Blackwell

Alexander, R.J. (2001b) Talk in Teaching and Learning: international perspectives QCA Seminar 2001 
Alexander, R.J. (2004) Towards Dialogic Teaching: Rethinking Classroom Talk Cambridge: Dialogus

Alexander, R.J. (2008) 'Culture, Dialogue and Learning' in Mercer, N and Hodgkinson, S (Eds) Exploring Talk in School London: Sage pp 91-115

Alexander, R.J. (Ed) (2010) Children, their World, their Education: final report and recommendations of the Cambridge Primary Review London: Routledge

Alexander, R.J. (2012) Improving oracy and classroom talk in English schools: achievements and challenges. (Version of a presentation given at the DfE seminar on Oracy, the National Curriculum and Educational Standards, 20 February 2012)

Bakhtin, M.M. (1981) The dialogic imagination: four essays. Austin: University of Texas Press

Barnes, D (1976) From Communication to Curriculum, Harmondsworth, Penguin

Barnes, D (1988) The Politics of Oracy in Maclure, M, Phillips, T and Wilkinson, A (Eds) Oracy Matters Milton Keynes: Open University Press pp 43-55

Barnes, D (2010) Exploratory Talk for Learning in Mercer, N and Hodkinson, E (Eds) Exploratory Talk in School London: Sage pp 1-17

Barnes, D, Britton, J and Rosen, H (1969) Language, the Learner and the School Harmondsworth: Penguin

Bex, T. and Watts, J.W. (2000) Standard English: the widening debate. London: Routledge

Britton, J (1994) 'Vygotsky's contribution to pedagogical theory' in Brindley, S (Ed) Teaching English London: Routledge pp 259-263

Bullock, A (1975) A language for life: report of the Committee of Inquiry appointed by the Secretary of State for Education and Science under the chairman ship of Sir Allan Bullock London: Her Majesty's Stationery Office (HMSO)

Burns, C. and Myhill, D. (2004) Interactive or inactive? a consideration of the nature of interaction in whole class teaching Cambridge Journal of Education 34.1, 35-48

Carter, R (Ed) (1990) Knowledge About Language and the Curriculum: The LINC Reader London: Hodder and Stoughton

Carter, R.A., 1999. 'Standard grammars, spoken grammars: Some educational implications'. in Bex, A.R. and Watts, R., (eds) Standard English: the continuing debate Routledge.

Carter, R (2002) 'The Grammar of Talk- Spoken English, Grammar and the Classroom' in QCA New Perspectives on Spoken English in the Classroom Conference papers $27^{\text {th }}$ June 2002 pp 6-13

Coffin, Caroline (2003). Spoken English and the question of grammar: the role of the functional model. In Qualifications and Currriculum Authority, New perspectives on English in the Classroom. London, UK:Qualifications and Curriculum Authority, pp. 14-18. 
Coles, J. (2005) Strategic Voices? Problems in developing oracy through 'interactive wholeclass teaching. Changing English,12:1, 113-123.

Coultas, V. (2015) Revisiting debates on oracy: classroom talk- moving towards a democratic pedagogy? Changing English, 22:1, 72-86

Corden, R (1988) Talk about oral skills in context London: Stanley Thornes

Cox, B (1991) Cox on Cox An English Curriculum for the 1990s London: Hodder and Stoughton

Crowley, T. (2003) Standard English and the politics of Language. Basingstoke: Palgrave Macmillan

Departmental Committee of the Board of Education (1921). The teaching of English in England (The Newbolt Report) London: HM Stationery Office

Department of Education (DfE) (2014) The National Curriculum for England. London: Her Majesty's Stationery Office (HMSO)

Department of Education and Science (DES) (1988) A Report of the Committee of Enquiry into the Teaching of English (The Kingman Report) London: Her Majesty's Stationery Office (HMSO)

Department of Education and Science (DES) (1989) English for ages 5 to 16 (The Cox Report) London: Her Majesty's Stationery Office (HMSO)

Department of Education and Science (DES) (1990) English in the National Curriculum London: Her Majesty's Stationery Office (HMSO)

Department for Education and Science (DfES) (2006) The Primary National Strategy Framework for Literacy London: DfES Publications

Department for Education and Science (DfES) (2006) The National Literacy Strategy Framework for Teaching London: DfES Publications

Department for Education and Science (DfES) (2006) Independent Review of the Teaching of Early reading (The Rose Report) London DfES

DfEE (1999) The National Curriculum London: Her Majesty's Stationery Office (HMSO)

DfES/QCA (2003a) Excellence and Enjoyment: a strategy for primary schools London: DfES

DfES/QCA (2003b) Primary National Strategy Speaking, Listening and Learning: working with children in Key stages One and Two London: DFES Publications

Edwards, D. and Mercer, N. (1987) Common knowledge: the development of understanding in the classroom Methuen

English, E., Hargreaves, L. and Hislam, J. (2002) pedagogical dilemmas in the National Literacy Strategy: primary teachers' perceptions, reflections and classroom behaviour Cambridge Journal of Education 32.1, 9-26 
Gibbons, S. (2015) The importance of oracy in Brindley, S and Marshall, B. (Eds) Masterclass in English education: transforming teaching and learning. London: Bloomsbury

Gove, M (2013) Michael Gove talks about the importance of Teaching available at https://www.gov.uk/government/speeches/michael-gove-speaks-about-the-importance-of-teaching accessed on May 12th 2016

Grudgeon, E, Hubbard, L, Smith, C and Dawes, L (2005) Teaching Speaking and Listening in the Primary School London: David Fulton

Halliday, M.A.K (1978) Language as Social Semiotic, London: Edward Arnold

Halliday, M.A.K. 1987. Spoken and written modes of meaning in Rosalind Horowitz and S. Jay Samuels (eds), Comprehending Oral and Written Language. New York: Academic Press. pp. 55-82.

Hardman, F (2011) Promoting a dialogic pedagogy in English teaching in Davison, J et al Debates in English Teaching. Oxon, Routledge

Hardman, F (2008) 'Teachers Use of Feedback in Whole-class and Group-based talk' in Mercer, N and Hodgkinson, S (Eds) Exploring Talk in School London: Sage pp 131-151

Howe, A. (1992) Making talk work. London: Hodder and Stoughton

Johnson, J (1994) The National Oracy Project (NOP) in Brindley, S (Ed) Teaching English London: Routledge pp 64-72

Evans, R. and Jones, D. (2008) Metacognitive approaches to developing oracy. Oxon: Routledge

Lefstein, A. \& Snell, J. (2014) Better than best practice: developing teaching \& learning through dialogue Oxon, Routledge

Mercer, N (1995) The Guided Construction of Knowledge Clevedon: Multilingual Matters

Mercer, N (2000) Words and Minds London, Routledge

Mercer, N and Hodgkinson, S (2008) The Value of Exploratory Talk in School London, Sage

Mercer, N and Dawes, L (2010) Speaking and Listening at Key Stage 2 and Beyond http://www.ite.org.uk/ite_topics/speaking_listening/005.html accessed

Lawlor, S (1988) Correct Core: Simple Curricula for English Maths and Science Centre for Policy Studies

Littleton, K. and Mercer, N. (2013). Interthinking: putting talk to work. Abingdon: Routledge.

Mercer, N. and Littleton, K. (2007) Dialogue and the Development of Children's Thinking. London: Routledge. 
Mroz, M., Smith, F. and Hardman, F. (2000) The discourse of the literacy hour Cambridge Journal of Education, 30.3, 379-390

Myhill, D. (2006) Talk, talk, talk: teaching and learning in whole class discourse Research Papers in Education 21.1 19-41

Norman, K (1992) Thinking Voices- The Work of the National Oracy Project London: Hodder and Stoughton

Qualifications and Curriculum Authority (QCA) (2003) New Perspectives on Spoken English in the Classroom Qualifications and Curriculum Authority (QCA)

Sinclair, J and Coulthard, M (1975) Towards an Analysis of Discourse. The English used by Teachers and Pupils Oxford, Oxford University Press

Smith, F. and Hardman, F. (2000) Evaluating the effectiveness of the national Literacy Strategy Educational Studies 26.3, 334-379

Vygotsky, L.S. (1962) Thought and language. Cambridge, MA: MIT.

Wilkinson, A (1965) 'Spoken English’ University of Birmingham Educational Review Occasional Publications No 2 